\title{
Correlates of blood pressure at age 18 in a cohort of Scottish adolescents
}

\author{
Helen Sweeting, Anthony Lever, Sally Macintyre
}

We report an analysis of blood pressure (BP) measured at age 18 in a cohort of adolescents in whom measurements were also made at age 15. Systolic BP was then independently associated with body weight and pulse rate. ${ }^{1}$ Follow up of this cohort at age 18 is of interest because measurements of BP made between this and age 25 predict hypertension and coronary disease in later life. ${ }^{2}$ Also, because information on birthweight is available in $90 \%$ of the cohort, we can assess the inverse relation noted previously between birthweight and BP in adults. $^{3}$

\section{Method}

Data are from the youngest of three cohorts of the West of Scotland Twenty-07 Study: Health in the Community. ${ }^{4}$ Baseline interviews in 1987 were with 100915 year old respondents (482 males and 527 females). At this time interviews were also conducted with one or both parents, if available; information on birthweight was obtained from biological parents only $(n=902)$ and on socioeconomic variables from social parents $(n=995)$. Follow up interviews were conducted in 1990 at age 18. The response rate was $90 \%$ (430 males and 478 females). Interviews and measurements on both occasions were by a specially trained nurse: BP using Hawksley random zero sphygmomanomaters, height using portable Nivot- oise stadiometers, weight using portable electronic scales.

At age 18, information was obtained from the adolescents on their position in the labour market (tertiary education, work/training or un/non-employment), smoking, drinking, exercise, diet, female contraceptive pill use, psychological well being, and recent life events. Room temperature was recorded.

\section{Results}

The only significant associations between BP and social, behavioural or psychological variables were higher systolic BP among male adolescents doing more exercise, and higher diastolic BP among non-smoking female adolescents and those who had experienced one or more recent life events categorised as undesirable.

Mean BP values at age 18 (table 1 ) represent a small rise of systolic BP in male adolescents from levels at 15 years (legend to table), a small decrease in diastolic BP in male adolescents and of systolic BP and diastolic BP in female adolescents (all significant).

Highly significant correlations were seen between $\mathrm{BP}$ at 15 and 18 years (table 1). This reflects the tendency of blood pressure to "track", subjects maintaining their position over time in the rank order of BP. ${ }^{2}$

Changes of BP between 15 and 18 years were related to changes of body weight (for
MRC Medical

Sociology Unit, 6 Lilybank Gardens, Glasgow, G12 8RZ H Sweeting

S Macintyre

Glasgow University

Department of

Medicine and

Therapeutics, Western

Infirmary, Glasgow,

G11 6NT

A Lever

Correspondence to: Dr Sweeting.

Accepted for publication 22 April 1997
Table 1 (A) Pearson's correlations and (B) multiple regression analysis (forced entry): associations with systolic and diastolic blood pressures at 18 years

\begin{tabular}{|c|c|c|c|}
\hline \multirow[t]{3}{*}{$\begin{array}{l}\text { A Pearson's } \\
\text { correlations }\end{array}$} & \multicolumn{3}{|c|}{ B Multiple regression analysis } \\
\hline & Enter birthweight & $\begin{array}{l}\text { Enter birthweight } \\
\text { and current weight }\end{array}$ & $\begin{array}{l}\text { Enter birthweight, current } \\
\text { weight and current height }\end{array}$ \\
\hline & $\beta \quad p$ Value & $\beta \quad p$ Value & $\beta \quad p$ Value \\
\hline
\end{tabular}

Male adolescents

Systolic BP (mm Hg) (115.8, SD 12.2) age 15 systolic $\mathrm{BP} \dagger$

birthweight

current weight

current height

Diastolic BP (mm Hg) (63.2, SD 13.4)

age 15 diastolic $\mathrm{BPt}$

birthweight

current weight

current height

Female adolescents

Systolic BP (mm Hg) (106.8, SD 11.6)

age 15 systolic $\mathrm{BP}+$

birthweight

current weight

current height

Diastolic BP (mm Hg) (61.9, SD 12.6)

age 15 diastolic $\mathrm{BP} \dagger$

birthweight

current weight

current height

$0.352^{\star \star \star}$

$-0.054$

$0.378^{\star \star \star}$

-0.054 NS

-0.117 *

$-0.126 \quad \star$
$0.382 \quad \star \star \star$

$0.167^{\star \star \star}$

$\begin{array}{ll}0.397 \star \star \star \star & 0.382 \\ & 0.036 \text { NS }\end{array}$

$0.182^{\star \star \star}$

0.021
$0.116^{\star}$

0.021 NS

$\begin{array}{ll}0.003 & \mathrm{~ns} \\ 0.116 & \star\end{array}$

0.037 NS

$-0.049$

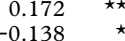

-Values at age 15: male SBP 114.4, SD 12.0; male DBP 65.9, SD 9.9; female SBP 108.8, SD 11.0; female DBP 66.4, SD 9.8. $\beta=$ Standardised (all variables expressed in $Z$ score form) regression coefficient; $\mathrm{p}=$ significance of $t$ test for $\beta$ not equal to zero: NS=not significant, ${ }^{\star}<0.05,{ }^{\star} \star<<0.01,{ }^{\star}{ }^{\star \star \star}<0.001$. 
systolic BP in male adolescents $r=0.266$, in female adolescents $r=0.175$, both $\mathrm{p}<.001$ ); for diastolic BP the relations were less close $(r=0.101, \mathrm{p}<.05$ in male adolescents; $r=0.143$, $\mathrm{p}<.01$ in female adolescents). A similar relation was seen between changes of BP and changes of body mass index ( $r$ values between 0.108 and 0.252 , all significant). There was no association between changes of $\mathrm{BP}$ and changes of height. This pattern of correlations reflects the well known relation between growth and BP in adolescents. ${ }^{2}$ The female adolescents may have shown weaker associations because growth had ceased between 15 and 18 years.

Neither BP at age 18 (table 1) nor change of BP between 15 and 18 were related significantly to birthweight. However, multivariate analyses (table 1) showed that after accounting for current weight, birthweight was related significantly and inversely to systolic BP. Additional analyses showed no significant interactions between birthweight and current weight in respect of age $18 \mathrm{BP}$.

\section{Discussion}

We confirm the positive relation of BP with current weight and growth rate in adolescents noted by many workers. An important question is whether there is also a significant negative relation of birthweight and $\mathrm{BP}$ at this age. Where allowance is made for current body weight, our study and others ${ }^{5}$ lend some support, and although the correlation of birthweight and current $\mathrm{BP}$ is not strong (table 1), it is demonstrable during the adolescent growth spurt when the positive relation of current weight and $\mathrm{BP}$ is particularly pronounced. Better assessment of the link with low birthweight should be possible at a third follow up of this cohort in early adulthood, when growth has ceased.

The authors wish to thank Patrick West, researcher with overall responsibility for the youth cohort, and Geoff Der for his statistical advice.

Funding: The West of Scotland Twenty-07 Study is funded by the Medical Research Council of Great Britain.

Conflicts of interest: none.

1 Macintyre S, Watt G, West P, Ecob R. Correlates of blood pressure in 15-year olds in the West of Scotland. F Epidemiol pressure in 15-year olds in the West

2 Lever AF, Harrap SB. Essential hypertension: a disorder of growth with origins in childhood? $\mathcal{F}$ Hypertens 1992;10 $101-20$.

3 Barker D, Osmond C, Golding J, Kuh D, Wadsworth M. Growth in utero, blood pressure in childhood and adult life, and mortality from cardiovascular disease. $B M \mathcal{F} 1989$; 298:587-91

4 Macintyre S, Annandale E, Ecob R, et al. The West of Scotand Twenty-07 Study: Health in the Community. In: Martin C, MacQueen D, eds. Readings for a new public health. Edinburgh: Edinburgh University Press, 1989;5674 .

5 Whincup P, Cook D, Papacosta O, Walker M. Birth weight and blood pressure: cross sectional and longitudinal relations in childhood. BMF 1995;311:773-6. 